Paper presented at PED 2010, NIST, Maryland USA, March 8-10 2010

\title{
Stairs or Lifts? - A Study of Human Factors associated with Lift/Elevator usage during Evacuations using an online Survey
}

\author{
M.J Kinsey, E.R Galea, and P.J Lawrence \\ Fire Safety Engineering Group (FSEG), \\ University of Greenwich, London, UK \\ Corresponding author: m.j.kinsey@gre.ac.uk
}

\begin{abstract}
This paper presents an overview of human factors data collected via an online survey related to the use of lifts (elevators) and stairs during both circulation and evacuation scenarios. Survey participants were presented with a series of hypothetical situations and asked how they would behave. The survey was split into two broad sections, the first dealing with normal circulation usage of lifts/stairs and the second dealing with evacuation usage of lifts/stairs. Detailed demographic information about each participant was also collected. In total some 468 people from 23 countries completed the survey. An overview of the survey and initial results are presented in this paper.
\end{abstract}

\section{Introduction}

How will people behave when given the option to use lifts during emergency evacuation situations within high-rise buildings? In countries such as the UK, Australia, Malaysia, China and USA, lifts are either being used or being considered for use as part of building evacuation systems. In past ad-hoc egress situations lifts have been used to good effect to assist in the rapid evacuation of highrise buildings [1]. In such cases lifts were not intended to form part of the evacuation system but were used by residents for rapid egress. Computer modelling also suggests that if used correctly, the combined use of lifts and stairs can speed up full building evacuation process by as much as $50 \%$ compared to the use of stairs alone [2]. However, in these modelling examples, due to lack of human factors data, ideal "compliant" occupant behaviour was assumed. This meant that all the agents that were designated to use the lifts waited to use the lifts for as long as required. However, how many people would actually consider using a lift rather than the stairs? How long would people wait for a lift? Some evidence suggests that when faced with large queues occupants will not be prepared to wait for lifts [3]. Under what conditions will people wait for the lift? Would people in different 
countries behave differently? Answers to these questions are essential if engineers are to realistically model building evacuation using lifts and design reliable evacuation systems in which both stairs and lifts are used.

While several studies have postulated human response to the use of lifts during evacuations $[4,5]$, certain studies have interviewed survivors who used lifts during real evacuations/drill $[1,3,6]$ and some studies have conducted surveys [6], there is still a lack of understanding regarding the key factors which influence human behaviour relating to lift/stair selection during evacuations. Indeed whilst past studies have provided insight into such behaviour, most have been narrow in their focus resulting in questionable general applicability, for example, focusing on narrow population age groups (e.g. students, elderly); involving populations with little or no experience of high-rise buildings; drawn from potentially biased populations (e.g. businesses involved in fire engineering), or from a very narrow cultural diversity. Further to this, very little publically accessible data pertaining to human factors associated with normal lift usage is available. Use of lifts for evacuations may be related to experiences and expectations drawn from normal lift usage and so an understanding of human factors associated with normal lift usage is considered important. To address the above issues and attempt to gain a better understanding of human factors associated with lift/stair use during circulation and evacuation scenarios, an online survey (http://fseg.gre.ac.uk/elevator) was developed, asking participants how they would behave with regards to lift/stair usage within a series of hypothetical situations. The use of a publically accessible online survey was intended to reach as wide an international audience as possible coming from a broad variety of different cultural backgrounds.

\section{Survey Description}

The survey was made available in two languages English and Chinese. The later was selected as it enabled a specific cultural group, other than English only speakers, to respond to the survey. In addition, in 2009 China possessed six of the world's ten tallest completed buildings and cities such as Shanghai and Beijing have a large number of high-rise residential and office buildings. The survey is split into three parts, the first addresses circulation issues, the second evacuation issues while the third part concerns requests participant demographic information. The survey requires approximately 20 minutes to complete. The first part of the survey explores the influence of travel distance, queues and groups on exit/stair choice. Here participants are requested to state the maximum number of floors they would consider walking on the stairs in a variety of situations. Each situation explored the influence of direction (travelling up/down), familiarity (being familiar/unfamiliar), trip purpose (being in a leisure/business activity) and time pressure (having/not having time pressure). The second part of the survey focused specifically on evacuation usage and informed participants that it was safe to use a lift 
during the hypothetical evacuation. Participants were then asked a series of questions related to whether they would consider using a lift and, if so, a variety of questions as to some of the influences effecting this selection and the amount of time they would wait for a lift.

\section{Participant Characteristics and Demographics}

In total 468 participants either fully or partially completed the survey, of which 424 provided complete main demographic information. Of all participants $60.6 \%$ (269) were male and 39.4\% (175) were female. Of all participants who provided age data $(\mathrm{N}=444)$, the average age was 35.0 years: $44.6 \%$ between $18-30$ years, $26.6 \%$ between $31-40$ years, $15.3 \%$ between $41-50$ years, $9.7 \%$ between $51-60$ years and $3.8 \%$ were over 60 years. Considering participants who provided their occupation $(\mathrm{N}=449)$ : $18.9 \%$ were students, $7.6 \%$ were from the fire safety/protection profession and $1.6 \%$ came from the lift industry. The remaining $71.9 \%$ of participant occupations were either classified as coming from other professions or non-specific (e.g. office worker, staff, assistant etc). Of all the participants, $63.5 \%$ confirmed that their place of work/study possessed lifts with these buildings varying from 2 to 78 floors with an average of 10.1 floors, with over half $(54.9 \%)$ of those buildings being over 5 floors in height. Approximately $15.6 \%$ of all participants had at least one lift in their place of residence, varying from 3 to 35 floors with an average of 10.8 floors in height, with approximately three quarters $(75.3 \%)$ of those buildings being greater than 5 floors in height. Whilst overall participants came from some 23 different countries, six countries made up approximately $88.9 \%$ of all participants: UK (30.8\%), China (25.9\%), US (12.8\%), Germany (11.1\%), Japan (5.6\%), Australia (2.8\%). Using the WHO (World Health Organisation) classification of body mass indexing (BMI), of the participants who provided plausible height/weight information $(\mathrm{N}=445), 6.7 \%$ were classed as underweight, $56.4 \%$ were normal weight, $24.7 \%$ were overweight, $11.0 \%$ were obese and just $1.1 \%$ were classed as being morbidly obese.

\section{Results - Circulation and Evacuation Usage}

Each section within the survey is based around a hypothetical scenario. The core part of the scenario description, unless stated otherwise, is identical for each question and consists of the following information:

- You are familiar with the layout of the building.

- The lifts/stairs are located in the same area.

- You are not carrying or wearing anything to restrict your movement. 
- A lift is not currently on your floor and you do not know how long you will have to wait for a lift to return.

\section{Circulation Usage}

The first part of the survey, addressing circulation behaviour, explored issues to do with vertical travel distance, queue length in the lift waiting area and group behaviour. Three specific variations of the core scenario were presented to the participants. Additional situational information relating to the nature of these various scenarios is presented in Table 1. Given these specific situations, participants were asked what is the maximum number of floors they would consider travelling on the stairs before electing to use a lift. Participant responses either stated that they always consider using the stairs, never consider using the stairs (always use the lift), or sometimes consider using the stairs (specifying a finite number of floors they would walk on the stairs). Answers to the various questions were further categorised according to: building familiarity, whether or not travel was time critical and whether or not the travel was for leisure or business. While these factors have varying influences upon the responses, due to space limitations these various categories have been collapsed into direction of travel and trip purpose with the average results presented in Table 2 .

Table 1. Additional situation information provided for each section.

\begin{tabular}{ccc}
\hline Base Case & Queues & Groups \\
\hline $\begin{array}{c}\text { You are alone in a lift } \\
\text { waiting area on your } \\
\text { floor. }\end{array}$ & $\begin{array}{c}\text { There are a number of people } \\
\text { in the lift waiting area on your } \\
\text { floor. }\end{array}$ & $\begin{array}{c}\text { You are travelling with a group of 2-4 } \\
\text { people. }\end{array}$ \\
& $\begin{array}{c}\text { The people in the group are all of } \\
\text { similar physical ability and fitness to } \\
\text { yourself. }\end{array}$ \\
& The lift waiting area on your floor is \\
& empty.
\end{tabular}

In the base case, $87.8 \%$ of the participants would always or sometimes consider using the stairs to travel down and $84.2 \%$ to travel up. This is rather a high percentage of people who would consider using the stairs, with slightly more participants prepared to travel down the stairs compared to up. On average participants were prepared to walk 2.0 floors further down than up, 6.7 floors down and 4.7 floors up.

When faced with a queue in the lift waiting area, slightly more participants would always or sometimes consider using the stairs compared to the base case, with $89.4 \%$ of participants always or sometimes consider using the stairs to travel down (compared with $87.8 \%$ ) and $87.3 \%$ to travel up (compared with $84.2 \%$ ). This highlights a slight decrease in attractiveness of the lift due to congestion in the waiting area. When faced with a queue, participants were prepared to walk 
slightly further up/down (mean 5.0/7.0 floors) compared to the base case (mean 4.7/6.7 floors).

When travelling in a small group, slightly fewer participants would consider using the stairs compared to the base case, with $81.0 \%$ of participants always or sometimes considering using the stairs to travel down (compared with 87.8\%) and $76.4 \%$ to travel up (compared with $84.2 \%$ ). This highlights a decrease in attractiveness of the stair when travelling in groups compared to the queue scenario where an increase was observed. On average participants were prepared to walk 5.3 floors down (median 4.0) and 4.2 floors up (median 3.0). This represents a $20.9 \%$ (1.4) and $10.6 \%$ (0.5) decrease in the number of floors participants would consider walking on the stairs in the down and up direction respectively compared to the base case. When travelling in groups there is a considerable reduction in the distance people are prepared to travel on stairs.

Table 2. Overall Combined Average Results Irrespective of Time Pressure or Familiarity for the Base, Queue and Groups cases.

\begin{tabular}{|c|c|c|c|c|}
\hline & & Base Case & Queues & Groups \\
\hline \multirow[t]{8}{*}{ Up } & Always use lift & $\begin{array}{c}15.8 \% \\
{[592]}\end{array}$ & $\begin{array}{c}12.7 \% \\
{[474]}\end{array}$ & $\begin{array}{c}23.5 \% \\
{[875]}\end{array}$ \\
\hline & Always consider & $3.7 \%$ & $4.5 \%$ & $4.3 \%$ \\
\hline & using Stairs & [138] & [169] & {$[161]$} \\
\hline & Sometimes consider & $80.5 \%$ & $82.8 \%$ & $72.1 \%$ \\
\hline & using Stairs & [3008] & [3091] & [2682] \\
\hline & Median Stair Travel (floors) & 3.8 & 4.0 & 3.0 \\
\hline & Mean Stair Travel (floors) & 4.7 & 5.0 & 4.2 \\
\hline & Total Frequency & 3738 & 3734 & 3718 \\
\hline \multirow{9}{*}{ Down } & & $12.2 \%$ & $10.6 \%$ & $19.0 \%$ \\
\hline & Aiways use IIIt & {$[450]$} & [392] & {$[701]$} \\
\hline & Always consider & $5.6 \%$ & $7.6 \%$ & $5.0 \%$ \\
\hline & using Stairs & {$[208]$} & {$[281]$} & [184] \\
\hline & Sometimes consider & $82.2 \%$ & $81.8 \%$ & $76.0 \%$ \\
\hline & using Stairs & [3036] & [3027] & [2799] \\
\hline & Median Stair Travel (floors) & 5.1 & 5.3 & 4.0 \\
\hline & Mean Stair Travel (floors) & 6.7 & 7.0 & 5.3 \\
\hline & Total Frequency & 3694 & 3700 & 3684 \\
\hline
\end{tabular}

\section{Evacuation Usage}

The evacuation section of the survey was intended to investigate whether participants would consider using a lift to evacuate if they were informed that it was acceptable to do so during an emergency, and if so, identify and quantify influencing factors that would cause them to redirect to use the stairs. For the evacuation base scenario the following additional information was provided to the participants:

- You are travelling alone. 
- You have been instructed that it is acceptable to use either a lift or stairs to evacuate from your building in emergency situations. During an evacuation you are free to choose to use a lift or stairs.

Of the participants who answered whether they would consider using a lift to evacuate $(\mathrm{N}=467)$, approximately a third (33.0\% (154)) ) said that they would consider using a lift. Thus, two thirds of the participants would not consider using a lift to evacuate, even though they knew it was acceptable to do so.

Of the participants who would consider using a lift and answered whether or not they would always use a lift (152), a small proportion $(7.2 \%$ (11)) said that they would always use a lift. Of the 154 participants who would consider using a lift, $78.6 \%$ (121) replied that the height of the floor they were on would influence their decision. These participants were then asked to specify a maximum/minimum number of floors above/below which they would not consider using the lift. Of the participants who specified a maximum number of floors they would be prepared to travel by lift (120), 46.7\% (56) answered that there was no maximum number of floors, $22.5 \%$ (27) answered 100+ floors, and the remaining $30.8 \%$ (37) specified a varying number of floors with an average maximum of 21.9 floors. Of the participants who specified a minimum number of floors they would be prepared to travel by lift (121), 9.9\% (12) answered that there was no minimum number of floors, $0.83 \%$ (1) answered $100+$, and the remaining $89.3 \%$ (108) specified a varying number of floors with an average minimum of 8.4 floors. When asked if the height of the building would influence their decision to use a lift $(\mathrm{N}=136)$, almost two thirds $(65.4 \%$ (89)) said that the height of the building would influence their decision. Of this group $(\mathrm{N}=86), 80.2 \%$ (69) said that the higher the building the more likely they would be to use a lift.

For the remaining evacuation related questions, the following additional scenario information was provided:

- You are instructed to evacuate from a multi-storey building.

- It is not a drill but you are not in immediate danger.

- You have a choice to use one of the 4 lifts servicing your floor or the stairs.

- Each lift has a capacity of 10 people.

- The lift waiting area on your floor is crowded with people.

Participants were then asked, given that they were located on progressively higher floor ranges in the building, would they consider using a lift to evacuate and if so, after arriving in the lift waiting area, what level of crowd size/density already waiting for the lift would cause them to redirect to use the stairs. To quantify the crowd density, six different crowd densities (ranging from A to F) were presented to the participants based on graphics generated by the vrEXODUS software, three of which are presented in Fig. 1. Participants where then asked for each floor range to specify the crowd density that would deter them from waiting for a lift and to estimate, providing the crowd density was below that stated level, how long 
they would be prepared to wait in the crowd for a lift before they decided to use the stairs.

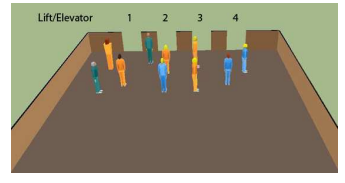

A: 10 people, $0.13 \mathrm{p} / \mathrm{m}^{2}$

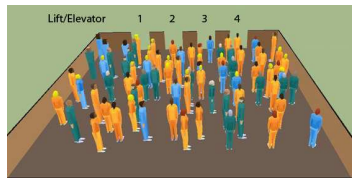

C: 80 people $1.0 \mathrm{p} / \mathrm{m}^{2}$

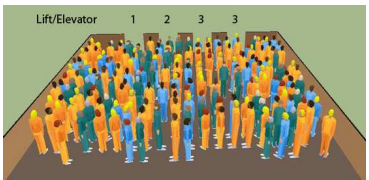

F: 200 people, $2.5 \mathrm{p} / \mathrm{m}^{2}$

Fig. 1. Three of the six Crowd Levels in the lift waiting area.

As with the circulation based questions, answers to the various questions were further categorised according to building familiarity. While there were some differences due to building familiarity, due to space limitations the responses have been collapsed into a single category and the average results are presented here (see Fig. 2 and Table 3).

Table 3. Frequency of participant responses that would consider using a lift as a function of crowd density (familiar and unfamiliar combined).

\begin{tabular}{|c|c|c|c|c|c|c|c|c|c|c|c|}
\hline \multirow[t]{2}{*}{$\begin{array}{l}\text { Floor } \\
\text { Range } \\
\text { Location }\end{array}$} & \multicolumn{2}{|c|}{$\begin{array}{l}\text { Proportion of partici- } \\
\text { pants that would con- } \\
\text { sider waiting to use } \\
\text { lift on a given floor } \\
\text { range }\end{array}$} & \multicolumn{9}{|c|}{$\begin{array}{l}\text { Of participants that would initially choose to use a lift, the } \\
\text { crowd density in the lift waiting area that would cause a pro- } \\
\text { portion of those participants to redirect to use the stairs. }\end{array}$} \\
\hline & Yes & No & $\#$ & $\begin{array}{l}\text { Doesn't } \\
\text { Matter }\end{array}$ & $\begin{array}{c}\mathrm{A} \\
\mathbf{0 . 1 3} \\
\mathrm{p} / \mathbf{m}^{2}\end{array}$ & $\begin{array}{c}\mathrm{B} \\
\mathbf{0 . 5} \\
\mathrm{p} / \mathrm{m}^{2}\end{array}$ & $\begin{array}{c}\mathrm{C} \\
\mathbf{1 . 0} \\
\mathbf{p} / \mathbf{m}^{2}\end{array}$ & $\begin{array}{c}D \\
1.5 \\
\mathbf{p} / \mathbf{m}^{2}\end{array}$ & $\begin{array}{c}E \\
\mathbf{2 . 0} \\
\mathbf{p} / \mathbf{m}^{2}\end{array}$ & $\begin{array}{c}\mathrm{F} \\
2.5 \\
\mathrm{p} / \mathrm{m}^{2}\end{array}$ & $\begin{array}{c}\mathrm{F}+ \\
2.5 \\
\mathrm{p} / \mathrm{m}^{2}+\end{array}$ \\
\hline $2-10$ & & & 38 & $\begin{array}{c}15.8 \% \\
{[6]}\end{array}$ & $\begin{array}{c}18.4 \% \\
{[7]}\end{array}$ & $\begin{array}{c}44.7 \% \\
{[17]}\end{array}$ & $\begin{array}{c}73.7 \% \\
{[28]}\end{array}$ & $\begin{array}{c}78.9 \% \\
{[30]}\end{array}$ & $\begin{array}{c}78.9 \% \\
{[30]}\end{array}$ & $\begin{array}{c}84.2 \% \\
{[32]}\end{array}$ & $\begin{array}{c}84.2 \% \\
{[32]}\end{array}$ \\
\hline $11-20$ & $\begin{array}{c}33.3 \% \\
{[114]}\end{array}$ & $\begin{array}{c}66.7 \% \\
{[228]}\end{array}$ & 114 & $\begin{array}{c}10.5 \% \\
{[12]}\end{array}$ & $\begin{array}{c}14.0 \% \\
{[16]}\end{array}$ & $\begin{array}{c}31.6 \% \\
{[36]}\end{array}$ & $\begin{array}{c}60.5 \% \\
{[69]}\end{array}$ & $\begin{array}{c}84.2 \% \\
{[96]}\end{array}$ & $\begin{array}{c}86.8 \% \\
{[99]}\end{array}$ & $\begin{array}{c}89.5 \% \\
{[102]}\end{array}$ & $\begin{array}{c}89.5 \% \\
{[102]}\end{array}$ \\
\hline $21-30$ & $\begin{array}{c}63.5 \% \\
{[216]}\end{array}$ & $\begin{array}{c}36.5 \% \\
{[124]}\end{array}$ & 214 & $\begin{array}{l}7.0 \% \\
{[15]}\end{array}$ & $\begin{array}{c}5.6 \% \\
{[12]}\end{array}$ & $\begin{array}{c}25.7 \% \\
{[55]}\end{array}$ & $\begin{array}{c}61.7 \% \\
{[132]}\end{array}$ & $\begin{array}{c}82.2 \% \\
{[176]}\end{array}$ & $\begin{array}{c}89.7 \% \\
{[192]}\end{array}$ & $\begin{array}{c}93.0 \% \\
{[199]}\end{array}$ & $\begin{array}{c}93.0 \% \\
{[199]}\end{array}$ \\
\hline $31-40$ & $\begin{array}{c}77.8 \% \\
{[256]}\end{array}$ & $\begin{array}{c}22.2 \% \\
{[73]}\end{array}$ & 252 & $\begin{array}{c}9.9 \% \\
{[25]}\end{array}$ & $\begin{array}{c}2.8 \% \\
{[7]}\end{array}$ & $\begin{array}{c}19.0 \% \\
{[48]}\end{array}$ & $\begin{array}{c}49.2 \% \\
{[124]}\end{array}$ & $\begin{array}{c}77.8 \% \\
{[196]}\end{array}$ & $\begin{array}{c}86.9 \% \\
{[219]}\end{array}$ & $\begin{array}{c}90.1 \% \\
{[227]}\end{array}$ & $\begin{array}{c}90.1 \% \\
{[227]}\end{array}$ \\
\hline $41-50$ & $\begin{array}{l}79.0 \% \\
{[260]}\end{array}$ & $\begin{array}{c}21.0 \% \\
{[69]}\end{array}$ & 254 & $\begin{array}{c}9.1 \% \\
{[23]}\end{array}$ & $\begin{array}{c}2.8 \% \\
{[7]}\end{array}$ & $\begin{array}{c}14.6 \% \\
{[37]}\end{array}$ & $\begin{array}{c}39.0 \% \\
{[99]}\end{array}$ & $\begin{array}{c}64.2 \% \\
{[163]}\end{array}$ & $\begin{array}{c}83.5 \% \\
{[212]}\end{array}$ & $\begin{array}{c}90.6 \% \\
{[230]}\end{array}$ & $\begin{array}{c}90.9 \% \\
{[231]}\end{array}$ \\
\hline $51-60$ & $\begin{array}{c}80.5 \% \\
{[265]}\end{array}$ & $\begin{array}{c}19.5 \% \\
{[64]}\end{array}$ & 257 & $\begin{array}{c}10.5 \% \\
{[27]}\end{array}$ & $\begin{array}{c}3.1 \% \\
{[8]}\end{array}$ & $\begin{array}{c}13.2 \% \\
{[34]}\end{array}$ & $\begin{array}{c}33.5 \% \\
{[86]}\end{array}$ & $\begin{array}{c}56.4 \% \\
{[145]}\end{array}$ & $\begin{array}{c}72.8 \% \\
{[187]}\end{array}$ & $\begin{array}{c}84.8 \% \\
{[218]}\end{array}$ & $\begin{array}{c}89.5 \% \\
{[230]}\end{array}$ \\
\hline
\end{tabular}

Presented in Table 3 is the overall proportion of participants that would consider using a lift/stair for each floor range. As the floor height increases the proportion of participants that would consider using the lift also increases. We note that approximately $10 \%$ of the population would use a lift even if located on the lowest floors i.e. 2-10. The proportion of the population that would use the lift increases to approximately $80 \%$ at floor range $31-40$ and remains at this level for the higher floor ranges. This suggests that when located on or above floors 21-30, the major- 
ity of people on each floor would elect to use the lift compared to the stairs. Above floor 30 , approximately $20 \%$ of the population are not prepared to use the lifts to evacuate irrespective of floor height.

In addition, presented within Table 3 is the cumulative proportion of those participants that would choose to redirect to use the stairs based on crowd density within the lift waiting area. We note that of those prepared to wait to use the lift given a crowd in the lift waiting area, an average $10.5 \%$ of the population would be prepared to wait for the lift, regardless of floor height or crowd density. Furthermore, the average crowd density that participants would be prepared to tolerate before redirecting to the stairs increases as the floor height increases. For a floor height of $2-10,70 \%$ of the population waiting for the lift would redirect to the stairs when the average congestion levels are between $B$ and $C\left(0.5 \mathrm{p} / \mathrm{m}^{2}\right.$ and $\left.1.0 \mathrm{p} / \mathrm{m}^{2}\right)$, while for a floor height of 21-30, this increases to between $C$ and $D\left(1.0 \mathrm{p} / \mathrm{m}^{2}\right.$ and $\left.1.5 \mathrm{p} / \mathrm{m}^{2}\right)$ and for a floor height of 51-60, this increases to between D and $\mathrm{E}(1.5$ $\mathrm{p} / \mathrm{m}^{2}$ and $2.0 \mathrm{p} / \mathrm{m}^{2}$ ). Participants who would consider using a lift for a given floor range were asked, providing the crowd level did not reach or exceed the density which would cause them to redirect, what was the maximum time they would be prepared to wait to use a lift. For each floor range a small number of participants (0\%-7\%) stated that they would wait for a lift for "as long as it takes" with an average proportion of $5.8 \%$ for all floor ranges. In addition, a small number of participants $(6.1 \%$ (14)) said that they would not be prepared to wait for a lift, regardless of floor height.

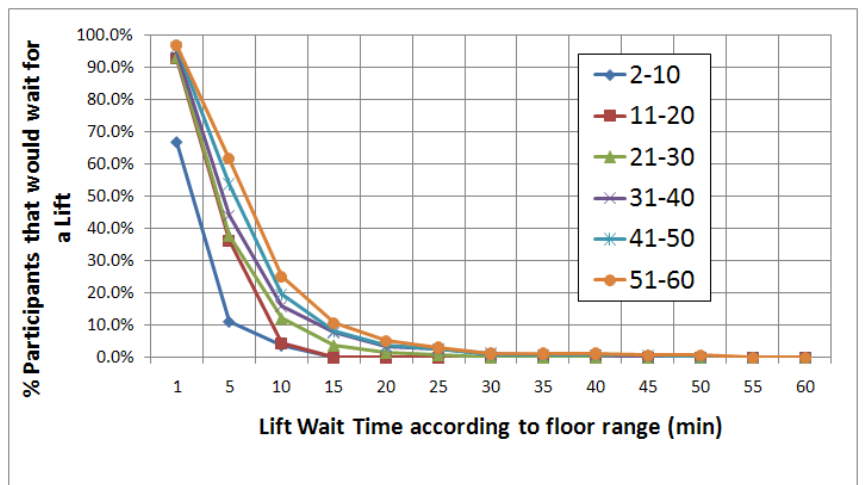

Fig. 2. Cumulative proportion of participants that would wait for a lift (grouped into 5 min intervals) for each floor range.

In Fig. 2 the normalised cumulative frequency distribution of the remaining participants who specified the maximum time they would be prepared to wait for a lift on each floor range can be seen. As the floor height increases the proportion of participants that would wait a longer amount of time in the lift waiting area also approximately increases. This reflects participants increased tolerance to waiting a 
longer amount of time for a lift on progressively higher floors in light of the added travel time and energy expenditure they would need to expend travelling on the stairs. Fig. 2 also suggests that the majority of participants who initially chose to use a lift in floor range 2-40 would only be prepared to wait between 1-5 minutes for a lift before redirecting to the stairs. For the floor range 40-60 the majority of participants would be prepared to wait between 5-10 minutes. For all floor ranges, approximately less than $10 \%$ of participants would be prepared to wait more than 15 minutes for a lift before redirecting to the stairs; highlighting participants intolerance to wait long periods of time for a lift during an evacuation.

\section{Conclusion}

This paper has presented an analysis of data collected from participant responses to an online survey in order to gain an understanding of human factors associated with lift/stair selection in both circulation and evacuation scenarios. In normal circulation conditions, between $90 \%-85 \%$ of the survey population would be prepared to use the stairs to travel down/up. On average participants were prepared to walk 6.7/4.2 floors in the down/up direction respectively. Results suggest that a queue in the lift waiting area does not influence these numbers greatly however, travelling in groups does. When travelling is a small group (up to four people), the percentage of the survey population prepared to use the stairs to travel down/up decreases to $80 \% / 76 \%$ and the distance they are prepared to walk down/up decreases to $4.8 / 3.2$ floors.

In evacuation conditions, despite being informed that the lifts were a safe and acceptable option, two thirds of the sample (308) said they would not consider using a lift to evacuate. This suggests that if buildings are being designed on the assumption that occupants will utilise lifts for evacuation, an extensive training campaign will be essential. This poses difficulties for buildings that are largely frequented by casual visitors. Of the participants whom would consider using a lift (152), less than $10 \%$ said that they would always use a lift, while over $75 \%$ (121) said that the height of the floor they were on would influence their decision to use a lift. The height of the building was also a significant factor in determining whether or not they would use the lift. Of the participants who specified a maximum number of floors they would be prepared to travel by lift (120), almost $70 \%$ (83) effectively indicated that there was no maximum number of floors while of those specifying a minimum number of floors, almost 90\% (108) specified a varying minimum number of floors with an average minimum of 8.4 floors. As the floor height increases the proportion of participants that would consider using the lift increases. Approximately $10 \%$ of the population would use a lift even if located below the $10^{\text {th }}$ floor. The proportion of the population that would use the lift increases to approximately $80 \%$ up to floor 40 and remains at this level even for higher floors. This suggests that approximately $20 \%$ of the population will 
not use a lift to evacuate irrespective of floor height. A very small proportion of participants stated that they would wait in a lift waiting area regardless of crowd density and/or would wait for "as long as it takes" for a lift to service their floor. However, the majority of participants indicated there was a critical level of crowd density in the lift waiting area which, if reached or exceeded, they would redirect to the stairs. Furthermore, this critical density appears to increase as the floor height increases; reflecting the decreased attractiveness of using the stairs on progressively higher floors. The majority of participants also specified a finite time they would be prepared to wait for a lift; while this was dependent on floor height (the higher the floor, the longer the acceptable wait time), less than $10 \%$ of participants were prepared to wait more than 15 minutes regardless of floor height.

These results clearly show that in evacuation situations, building occupants are prepared to utilise lifts for evacuation but that this is strongly dependent on floor height, crowd density and expected lift wait time. Participants in the study clearly exhibit anticipatory behaviour and would expect a given level of service from an lift system during an evacuation. Further analysis of the survey data is currently underway examining the impact of pedestrian characteristics such as age, gender, country, building familiarity etc on both circulation and evacuation behaviours. The data is being used to enhance the agent based model associated with lift usage within the evacuation modelling software buildingEXODUS.

\section{References}

1. Sekizawa, A., Ebihara, M., Notake, H., Kubota, K., Nakano, M., Ohmiya, Y., Kaneko, H.: Occupants' behaviour in response to the high rise apartment fire in Hiroshima City, Fire and Materials, (1999).

2. Kinsey, M.J., Galea, E.R., Lawrence, P.J.: Investigating the use of lifts for high-rise building evacuation through computer simulation, Proc $4^{\text {th }}$ Int Symp on Human Behaviour in Fire Conference, pp85-96, (2009).

3. Galea, E.R., Shields, J., Canter D., Boyce, K., Day, R., Hulse, L, Siddiqui A., Summerfield, L., Marselle, M., and Greenall, P.: Methodologies employed in the Collection, Retrieval and Storage of Human Factors Information Derived from First Hand Accounts of Survivors of the WTC Disaster of 11 September 2001, Journal of Applied Fire Science. Vol 15, Number 4, 253-276, (2006).

4. Klote, J. H. and Alvord, D. M. and Levin, B. M. and Groner, N. E.: "Feasibility and Design Considerations of Evacuation by Lifts", NISTIR 4870, (1992).

5. Groner, N.E and Levin, B.M.: Human Factors Considerations in the Potential for Using Lifts in Building Emergency Evacuation Plans, NIST 94-656, (1992).

6. Heyes, E.: "Human Behaviour Considerations", Proc $4^{\text {th }}$ Int Symp on Human Behaviour in Fire Conference, pp73-84, (2009). 